\title{
Characterization of Storage Energy for Rocks Based on Acoustic Wave Velocity Measurement
}

\author{
Chunde $\mathrm{Ma}^{1,2}$, Chunzhi Guo ${ }^{1}$, Yanan Zhou ${ }^{1}$, Zelin Liu ${ }^{1}$ and Shan Long ${ }^{1}$ \\ ${ }^{1}$ School of Resources and Safety Engineering, Central South University, Changsha 410083, Hunan, China; \\ ${ }^{2}$ Advanced Research Center, Central South University, Changsha 410083, Hunan, China
}

\begin{abstract}
To quantitatively characterize the stored energy in the rock. In the elastic range, the fluctuation characteristics and energy of marbles, granites, and red sandstones subjected to different stresses were studied, and the variation laws of wave velocity-stress, stress-energy of three types of rocks were analyzed and compared, and studied the feasibility of using the bridge of the longitudinal wave speed to characterize energy. The results show that after the three kinds of rocks are repeatedly loaded to $70 \%$ of their uniaxial compressive strength, 1) the longitudinal wave velocity and stress of the three rocks meet the established linear model. Comparing the fitted initial wave speed with the measured wave speed, the accuracy of red sandstone is lower than that of marble and granite; 2) The stress and energy are in agreement with the established composite exponential model, and the red sandstone has higher dissipation energy than marble and granite. 3) Through the model established by the unloaded wave velocity-stress and stress-elasticity, a relation model between the unloaded wave velocity and the elasticity is obtained, indicating the feasibility of using the wave velocity to characterize the energy. Based on this, a more feasible method of testing the quantitatively characterization of wave velocity for rock energy storage in the laboratory is proposed, and the test results also show that hard rock is more suitable than soft rock to quantify the stored energy in this way.
\end{abstract}

Keywords-unloading wave velocity; elastic energy; linear model; composite exponential model; quantitative characterization

\section{INTRODUCTION}

The energy stored in the underground rock mass is a physical quantity that cannot be directly observed but actually exists. When the elastic energy stored in it (especially in hard rock) reaches a relatively high level, under the right conditions, disasters such as rock bursts may be triggered ${ }^{[1-2]}$. Many scholars at home and abroad have developed rock heights. A lot of research has been done on the mechanism of rock damage and the prediction and prevention of disasters in energy storage damage ${ }^{[3-5]}$. In recent years, some scholars have proposed to change damage into benefits, transform rock mass high-stress energy storage into a kind of energy for controlled release and benign use, and try to carry out passive research on some of the deep-seated disasters for active use, such as $\mathrm{Li}$. The report on the disaster control and fragmentation and mutagenesis of the high-stress stress in deep-well hard rock mining by Yu Bing et al ${ }^{[6-7]}$. The benign application of rock energy storage not only can effectively reduce the occurrence of disasters caused by the sudden release of energy, but also can use the rock energy. However, there are a series of technical problems to be solved. One of the key issues is how to deal with deep rock masses. Accurate quantitative characterization of energy storage. In recent years, scholars have conducted a large number of internal energy conversion and failure mechanisms under different conditions for the evolution of loaded energy ${ }^{[8-10]}$. Previous studies have mostly focused on the evolution of their internal energy under different conditions. The law is biased towards qualitative analysis, and for the rational regulation of the energy of deep high-stress rock masses, it is necessary to be able to control its specific amount, and the energy stored in the rock mass is to be quantitatively controlled. Cai Meifeng et al ${ }^{[11]}$ used a non-linear three-dimensional finite element program to calculate the stress and displacement state of surrounding rock in the prediction of rock burst in the Linglong Gold Mine. However, this method is cumbersome. Therefore, this study intends to use an indirect physical quantity-stress to establish a link between the quantifiable measured rock mass energy storage and the unquantifiable rock mass energy storage, and indirectly to the rock through wave velocity. Body energy storage for quantitative characterization and description.

\section{EXPERIMENTAL EQUIPMENT AND METHOD}

In this experiment, the U.S. MTS 815 mechanical experiment system and the MTS Ultrasonic Velocity sensors device for wave velocity measurement were used to measure a $\mathrm{P}$ wave (P-wave) wave velocity and two $\mathrm{S}$-wave (transverse wave) wave speeds of a rock sample. Only one of them was used in this experiment. $P$ wave. In this experiment, three types of typical rocks were chosen as research objects: red sandstone, marble, and granite, and they were processed into standard specimens with a diameter of $50 \mathrm{~mm}$ and a height of $100 \mathrm{~mm}$. Before the test, basic physical and mechanical parameters were tested on these types of rocks. See Table I:

TABLE I. THREE KINDS OF ROCK PHYSICAL AND MECHANICAL PARAMETERS

\begin{tabular}{|c|c|c|c|c|c|}
\hline $\begin{array}{c}\text { Rock } \\
\text { category }\end{array}$ & $\begin{array}{c}\text { Density } \\
\left(\mathrm{kg} / \mathrm{cm}^{3}\right)\end{array}$ & $\begin{array}{c}\text { Uniaxial } \\
\text { compressive } \\
\text { strength } \\
(\mathrm{MPa})\end{array}$ & $\begin{array}{c}\text { Elastic } \\
\text { strength } \\
\text { ceiling } \\
(\mathrm{MPa})\end{array}$ & $\begin{array}{c}\text { Elastic } \\
\text { Modulus } \\
(\mathrm{GPa})\end{array}$ & $\begin{array}{c}\text { Poisson's } \\
\text { ratio }\end{array}$ \\
\hline marble & 2710 & 105 & 84 & 65 & 0.24 \\
\hline granite & 2632 & 121 & 96 & 52 & 0.26 \\
\hline $\begin{array}{c}\text { red } \\
\text { sandstone }\end{array}$ & 2426 & 54 & 43 & 12 & 0.21 \\
\hline
\end{tabular}

This study only qualitatively and quantitatively studied the rock's elastic range, and loaded rock to $70 \%$ of its uniaxial compressive strength (to ensure that it is within the elastic range). In order to eliminate the impact of the first loading and unloading on the wave velocity ${ }^{[12]}$, the three rock samples are first loaded and unloaded repeatedly, and then the 
corresponding wave velocity waveforms are recorded and processed every $10 \mathrm{kN}$, which can be obtained under various pressures. The longitudinal wave speed of the rock sample. The specific amount of energy stored in the rock can be obtained by calculating the area under the stress-strain curve. As shown in Figure I, the sum of uid and uie is the stored energy density, and the product of volume and volume is the stored value. Energy value.

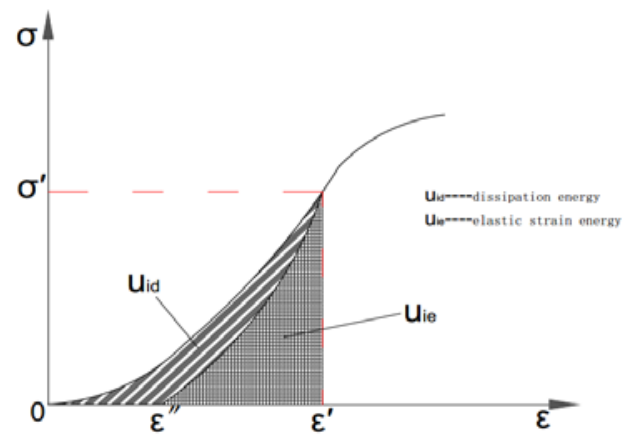

FIGURE I. STRESS-STRAIN CURVE UNDER THE AREA

\section{RESULTS AND ANALYSIS}

\section{A. The Relationship between Wave Speed and Stress}

The variation of wave velocity with stress after multiple loading and unloading of marble, granite and red sandstone is shown in Figure II.

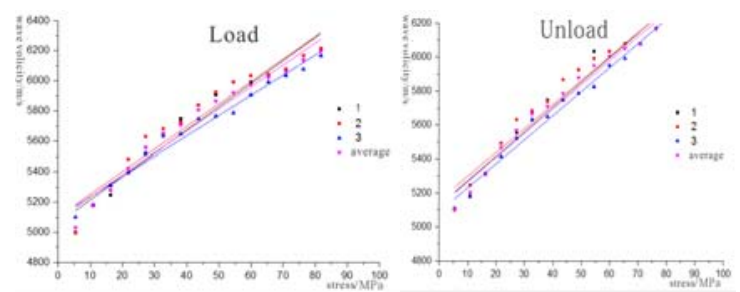

(a) marble
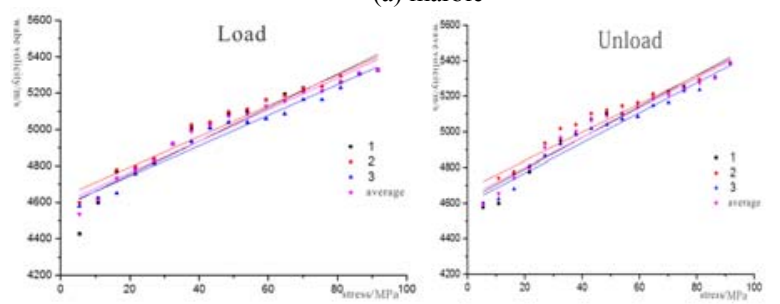

(b) granite

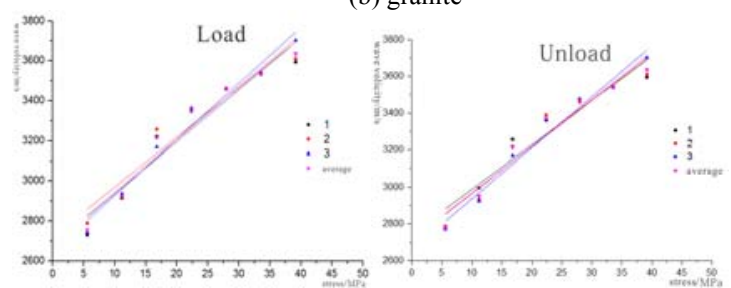

(c) red sandstone

FIGURE II. RELATIONSHIP BETWEEN WAVE VELOCITY AND STRESS UNDER LOADING AND UNLOADING

From the experimental results, on the one hand, it can be seen that the wave velocity of all three rocks increases with the increase of stress in the elastic range, and decreases with the decrease of stress under unloading condition, and the unloading wave speed is generally higher than that of loading Wave velocity. On the other hand, The average wave speed growth rates of marble, granite, and red sandstone are respectively $0-0.7 \%, 0-1.2 \%$, and $0-1.1 \%$ after three types of rocks have been repeatedly loaded and unloaded, This shows that after repeated loading and unloading of the rock, the loading wave velocity will be close to the unloading wave velocity. This provides a basis for establishing a model of wave-stress between loading and unloading conditions.

Fitting the data between the wave velocity and the stress accordingly, it is found that the linear model fits well. which is:

$$
v=k_{1} \sigma+v_{0}
$$

Where: v for a stress wave velocity, $\mathrm{m} / \mathrm{s} ; \quad \sigma$ for a loading (or unloading) moment of rock stress, $\mathrm{MPa}$; v0 for the initial wave velocity, $\mathrm{m} / \mathrm{s} ; \mathrm{k} 1$ for the coefficient. and the experimental data are fitted as shown in Table II, Since unloading is more meaningful than loading, only the unloaded fit is listed here (below).

TABLE II. RELATIONSHIP BETWEEN WAVE VELOCITY AND STRESS FITTING TABLE

\begin{tabular}{|c|c|c|c|c|}
\hline \multicolumn{2}{|c|}{$\begin{array}{c}\text { Rock sample loading and } \\
\text { unloading }\end{array}$} & \multirow{2}{*}{$\frac{\mathrm{K}_{1}(\mathrm{~m} / \mathrm{MPa} \cdot \mathrm{s})}{14.49}$} & \multirow{2}{*}{$\frac{\mathrm{v}_{0}(\mathrm{~m} / \mathrm{s})}{5102}$} & \multirow{2}{*}{$\begin{array}{c}\begin{array}{c}\text { Correlation } \\
\text { coefficient }(\mathrm{R})\end{array} \\
0.977\end{array}$} \\
\hline \multirow{4}{*}{ marble } & 1- unload & & & \\
\hline & 2- unload & 14.08 & 5106 & 0.976 \\
\hline & 3- unload & 14.14 & 5088 & 0.993 \\
\hline & $\begin{array}{l}\text { average - } \\
\text { unload }\end{array}$ & 14.24 & 5123 & 0.986 \\
\hline \multirow{4}{*}{ granite } & 1- unload & 8.77 & 4616 & 0.974 \\
\hline & 2- unload & 7.97 & 4679 & 0.969 \\
\hline & 3- unload & 8.45 & 4600 & 0.984 \\
\hline & $\begin{array}{l}\text { average - } \\
\text { unload }\end{array}$ & 8.40 & 4632 & 0.979 \\
\hline \multirow{4}{*}{$\begin{array}{c}\text { red } \\
\text { sandstone }\end{array}$} & 1- unload & 24.05 & 2746 & 0.961 \\
\hline & 2- unload & 25.00 & 2717 & 0.967 \\
\hline & 3- unload & 27.59 & 2660 & 0.986 \\
\hline & $\begin{array}{l}\text { average - } \\
\text { unload }\end{array}$ & 25.55 & 2708 & 0.975 \\
\hline
\end{tabular}

From the results in Table II, On the one hand, the k1 of red sandstone fluctuates greatly, and the k1 of granite and marble is relatively stable. On the other hand, the average wave speeds of marble, granite and red sandstone measured by non-metallic ultrasonic detector before the experiment are $5025 \mathrm{~m} / \mathrm{s}, 4624 \mathrm{~m} / \mathrm{s}$ and $2688 \mathrm{~m} / \mathrm{s}$ respectively, the error is $0.69 \%-1.61 \%, 0.17 \%-1.21 \%$, and $0.29 \%-2.16 \%$. Compared to the fitted wave speeds, It can be seen that the initial wave velocity error values for the marble and granite fittings are as follows: It is lower than red sandstone. The three rock correlation coefficients are stable between 0.963 and 0.993 . The overall fitting effect is very good, and it can be considered that the stress and wave velocity conform to the established linear model. 


\section{B. The Relationship between Stress and Energy}

Rocks store energy under pressure and release elastic energy under unloading conditions. During a loading and unloading process, a portion of dissipative energy is formed [13]. It can be seen from Figure III that the curve shows a non-linear growth, and the growth rate of the entire curve is basically unchanged. The average elastic energy corresponding to marble, granite and red sandstone is $8.50 \mathrm{~J}$, $13.35 \mathrm{~J}$ and $8.50 \mathrm{~J}$, corresponding to Dissipation energy is $0.63 \mathrm{~J}, 0.71 \mathrm{~J}$, and $1.04 \mathrm{~J}$. It can be seen that the average stored energy and elastic energy of marble and red sandstone are approximately equal, but they are all smaller than that of granite. The dissipative energy of red sandstone is larger than that of marble and granite. . The figure also shows that for marble and granite, after repeated loading and unloading for many times, the dissipation energy between loading and unloading is small, while the red sandstone has a relatively large dissipation energy, indicating marble and granite. The texture is denser and contains less voids and crevices. Therefore, the energy consumed by the friction between the rock particles is very small, while the red sandstone texture is sparse and the rock particles are large. The energy consumed by the friction increases, and the dissipation energy also increases.

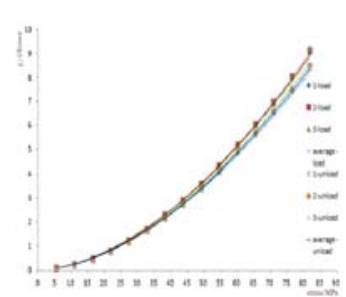

(a) marble

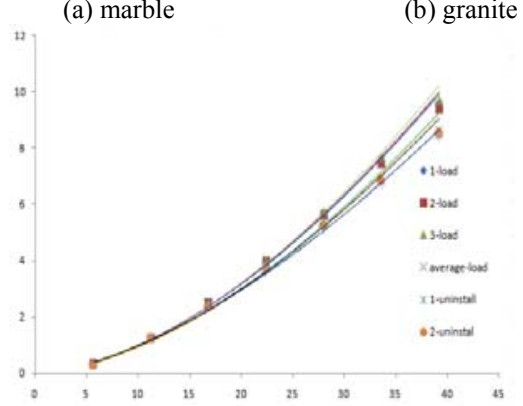

(c) red sandstone

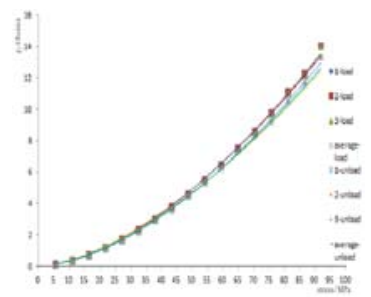

(b) granite
FIGURE III. THE RELATIONSHIP BETWEEN STRESS AND ENERGY AFTER LOADING AND UNLOADING

In order to find the functional relationship between stress and energy, fitting the data of the three rocks shows that the fitting power function fitting effect is very good. Which is:

$$
\mathrm{W}=k_{2} \sigma^{\alpha}
$$

Where: $\mathrm{W}$ is the energy of the rock, $\mathrm{J}$; the meaning of $\sigma$ is the same as above; $\alpha$ is the composite power exponent; $\mathrm{k} 2$ is the coefficient; and the experimental data are fitted as shown in Table III, It can be seen that the $\mathrm{k} 2$ and $\alpha$ values of marble and granite are relatively stable, while the $\mathrm{k} 2$ and $\alpha$ values of red sandstone have relatively large fluctuations. This is due to the large dissipative energy of red sandstone. However, the overall data fitting effect is very good, and the correlation coefficient is between 0.998-0.999. Therefore, it can be considered that the stress and energy conform to the established composite power function model.

TABLE III. RELATIONSHIP BETWEEN STRESS AND ENERGY FITTING TABLE

\begin{tabular}{|c|c|c|c|c|}
\hline \multicolumn{2}{|c|}{$\begin{array}{l}\text { Rock sample } \\
\text { loading and } \\
\text { unloading }\end{array}$} & $\begin{array}{c}\mathrm{k}_{2} \\
(\mathrm{~m} / \mathrm{MPa} \cdot \\
\mathrm{s})\end{array}$ & $\begin{array}{c}\text { Power } \\
\text { index } \\
\alpha\end{array}$ & $\begin{array}{c}\text { Correlation } \\
\text { coefficient( } \\
\text { R) }\end{array}$ \\
\hline \multirow{4}{*}{$\begin{array}{c}\text { marbl } \\
\mathrm{e}\end{array}$} & 1- unload & 0.003 & 1.760 & 0.998 \\
\hline & 2- unload & 0.003 & 1.757 & 0.998 \\
\hline & 3- unload & 0.003 & 1.794 & 0.999 \\
\hline & $\begin{array}{c}\text { average - } \\
\text { unload }\end{array}$ & 0.003 & 1.770 & 0.998 \\
\hline \multirow{4}{*}{$\begin{array}{c}\text { granit } \\
\mathrm{e}\end{array}$} & 1- unload & 0.006 & 1.690 & 0.999 \\
\hline & 2- unload & 0.008 & 1.621 & 0.998 \\
\hline & 3- unload & 0.007 & 1.632 & 0.998 \\
\hline & $\begin{array}{c}\text { average - } \\
\text { unload }\end{array}$ & 0.007 & 1.668 & 0.999 \\
\hline \multirow{4}{*}{$\begin{array}{c}\text { red } \\
\text { sandst } \\
\text { one }\end{array}$} & 1- unload & 0.020 & 1.671 & 0.995 \\
\hline & 2- unload & 0.019 & 1.684 & 0.994 \\
\hline & 3- unload & 0.024 & 1.595 & 0.999 \\
\hline & $\begin{array}{c}\text { average - } \\
\text { unload }\end{array}$ & 0.021 & 1.648 & 0.997 \\
\hline
\end{tabular}

C. Velocity Characterization of Elastic Energy

For materials such as rock, the elastic energy-stress curve more reflects the inherent properties of the material and is directly related to rock lithology. The use of unloaded wave velocity-stress curve and elastic energy-stress curve can well reflect the rock energy storage characteristics. Therefore, a wave velocity characterization method for elastic energy is established here.

In the previous discussion, the relationship between unloading wave velocity-stress and stress-elastic energy has been established. Therefore, the function formula of these two models can find the function of the wave velocity and energy as follows:

$$
\mathrm{W}=k_{2}\left(\frac{v-v_{0}}{k_{1}}\right)^{\alpha}
$$

In order to verify the rationality of the established model, it is necessary to compare the theoretical values of three kinds of rock energy with the actual values. It should be noted that the fitted data in the formula are all within a certain range. Therefore, in order to make a better comparison, the coefficients of the data average fitting are used here to bring into the corresponding formulas, and the average of the specific coefficients is shown in Table II and Table III above.

$$
\mathrm{W}=0.003\left(\frac{v-5085}{14.24}\right)^{1.770}
$$




$$
\begin{aligned}
& \mathrm{W}=0.007\left(\frac{v-4624}{8.40}\right)^{1.668} \\
& \mathrm{~W}=0.021\left(\frac{v-2688}{25.55}\right)^{1.648}
\end{aligned}
$$

\begin{tabular}{|c|c|c|c|c|c|c|c|c|}
\hline \multicolumn{3}{|c|}{ Marble } & \multicolumn{3}{|c|}{ Granite } & \multicolumn{3}{|c|}{ Red sandstone } \\
\hline $\mathrm{V}$ & $\mathrm{W}_{\text {theoretical value }}$ & $\begin{array}{c}\mathrm{W}_{\text {actual }} \\
\text { value }\end{array}$ & $\mathrm{V}$ & $\begin{array}{c}\mathrm{W}_{\text {theoretical }} \\
\text { value }\end{array}$ & $\begin{array}{c}\mathrm{W}_{\text {actual }} \\
\text { value }\end{array}$ & $\mathrm{V}$ & $\begin{array}{c}\mathrm{W}_{\text {theoretical }} \\
\text { value }\end{array}$ & $\begin{array}{c}\mathrm{W}_{\text {actual }} \\
\text { value }\end{array}$ \\
\hline 6213.00 & 8.448 & 8.496 & 5385.00 & 13.196 & 13.351 & 3610 & 8.088 & 8.499 \\
\hline 6167.00 & 7.038 & 7.523 & 5306.00 & 11.601 & 11.681 & 3540 & 6.795 & 6.819 \\
\hline 6078.00 & 6.097 & 6.593 & 5274.67 & 10.789 & 10.553 & 3474 & 5.359 & 5.220 \\
\hline 6049.33 & 5.806 & 5.714 & 5241.33 & 9.615 & 9.281 & 3362 & 3.781 & 3.711 \\
\hline 6006.67 & 5.385 & 4.907 & 5207.33 & 8.059 & 8.309 & 3219 & 2.391 & 2.372 \\
\hline 5951.00 & 4.456 & 4.136 & 5190.00 & 7.647 & 7.370 & 2935 & 1.025 & 1.239 \\
\hline 5878.67 & 3.605 & 3.420 & 5138.00 & 6.341 & 6.255 & 2773 & 0.167 & 0.336 \\
\hline 5787.00 & 3.239 & 2.760 & 5106.67 & 5.530 & 5.279 & & & \\
\hline 5711.33 & 2.458 & 2.175 & 5088.00 & 4.608 & 4.422 & & & \\
\hline 5666.00 & 2.032 & 1.646 & 5063.67 & 3.984 & 3.540 & & & \\
\hline 5570.00 & 1.700 & 1.178 & 5003.33 & 3.195 & 2.927 & & & \\
\hline 5467.00 & 1.312 & 0.777 & 4967.00 & 2.555 & 2.176 & & & \\
\hline 5312.00 & 0.611 & 0.449 & 4889.67 & 2.038 & 1.614 & & & \\
\hline 5203.33 & 0.263 & 0.211 & 4799.33 & 1.410 & 1.107 & & & \\
\hline 5105.33 & 0.064 & 0.080 & 4752.33 & 0.589 & 0.697 & & & \\
\hline & & & 4694.67 & 0.121 & 0.372 & & & \\
\hline & & & 4668.00 & 0.036 & 0.143 & & & \\
\hline
\end{tabular}

TABLE IV. THE CORRESPONDENCE TABLE OF WAVE VELOCITY-ENERGY

From the above table, it can be seen that, as a whole, the theoretical energy calculated by the established model has little difference from the real energy value, and the fitting effect is good. It is clearly shown that the energy of rock increases with the increase of the wave speed, and the greater the wave speed, the better the fitting effect. This is because when the wave velocity is large, it corresponds to the elastic phase of the rock, so the fitted effect is obtained. It is also best. However, when the wave speed is low, all three types of rock exist compaction stages. Although they are loaded and unloaded many times, they still have a small amount of plastic properties, which leads to a small difference between the energy represented by the wave velocity and the true value energy. In addition, it can be seen from the correspondence table between the three types of rock samples that the accuracy of marble and granite is higher, and the accuracy of red sandstone is relatively lower. Therefore, it is also illustrated that hard rock is more suitable for adopting wave velocity than soft rock. Characterize the energy stored in your own rock.

\section{CONCLUSION}

1) After fitting the wave velocities and stresses of the three rocks, the linear model fitting effect is better. The accuracy of the red sandstone is lower than that of the measured wave velocity when the fitted initial wave velocity is compared with the measured wave velocity Rock and granite, but on the whole, the wave velocity-stress of all three rocks conform to
The wave velocity-energy function formula of marble, granite, red sandstone and its correspondence table. the linear model.

2) When the three kinds of rock increase to $70 \%$ of the maximum stress, the corresponding energy and elastic energy of granite are greater than that of marble and red sandstone. Red sandstone has higher dissipation energy than marble and granite. Fitting the data between stress and energy shows that the compound power function has the best righting effect, and the three kinds of rocks are generally consistent.

3) The functional relationship between wave velocity and elastic energy is established and verified. The effect is good. The parameter of wave velocity can be used to characterize the elastic energy of rock. It also shows that hard rock is more suitable for quantitatively characterizing stored energy than soft rock with higher accuracy and accuracy.

\section{ACKNOWLEDGEMENT}

Deep rock mechanics and mining theory funded project (2016YFC0600706), Hunan provincial natural science fund project (2015JJ2172).

\section{REFERENCES}

[1] ZHANG Zhi-zhen, GAO Feng., 2012, Research on nonlinear characteristics of rock energy evolution under uniaxial compression[J]. Chinese Journal of Rock Mechanics and Engineering, 31(6):1198-1207.

[2] GUO Jian-qiang, LIU Xin-rong, WANG Jun-bao, HUANG Zhi-hong., 2016, Strength criterion of rock based on elastic strain energy[J]. Rock and Soil Mechanics., 2:129-136. 
[3] YANG Jian, WANG Lianjun., 2005,Experimental Study on Acoustic Emission of Rockburst Mechanism[J]. Rock Mechanics and Rock Engineering, 24(20):3796-3802.

[4] M.Cai, P.K. Kaiser, H.Morioka., 2007, FLAC/PEC coupled numerical simulation of AE in large-scale underground excavations[J].International Journal of Rock Mechanics and Mining Sciences., 4(44):550-564.

[5] CHEN Yang, QI Xiao-bo, CAI Xin-bin, SHEN Yu-peng., 2009, Application of Extension Comprehensive Evaluation Method in Rock-burst Discrimination[J]. Journal of Beijing Jiao tong University., 33(1):99-108.

[6] LI Xi-bing, YAO Jin-rui, DU Kun., 2013, Preliminary Study on Induced Fracturing Non-Explosive Continuous Mining in High Stress and Hard Rock Mines-Take Kai-yang Phosphate as an example[J]. Rock Mechanics and Rock Engineering., 32(6):1101-1111.

[7] LI Xi-bing, GONG Feng-qiang, DU Feng, LI Di-yuan.,2016 Progress of Experimental Research on Rock-burst Occurred under Dynamic Disturbance of High Stress Rock Mass[J]. Technology Innovation Guide., 15:173-173.

[8] LIANG Cang-yu, LI Xiao, WANG Sheng-xing, LI Shou-ding, E Jian-ming. 2012, Research on the rate dependence and energy mechanism of uniaxial compression stress - strain $\operatorname{rock}[\mathrm{J}]$. Rock Mechanics and Rock Engineering., 31(9):1830-1938.

[9] YANG Sheng-qi, XU Wei-ya, SU Cheng-dong. 2007, Study on deformation and energy characteristics of marble under triaxial deformation[J]. Engineering Mechanics., 24(1):136-142.

[10] XU Jiang, ZHANG Yuan, YANG Hong-wei, WANG Jin-neng., 2011, Energy evolution of deformation and damage of sandstone under cyclic pore water pressure[J]. Rock Mechanics and Rock Engineering., 30(1):141-148

[11] CAI Mei-feng, WANG Jin-an, WANG Shuang-hong., 2001, Rock mass energy analysis and rock burst comprehensive prediction of deep mining in Linglong Gold Mine[J]. Rock Mechanics and Rock Engineering., 20(1):38-42.

[12] LI Gao-yong. ,2013 Research on Correlation between Velocity and Stress in Sandstone in Real Time[D]. Lanzhou: Lanzhou University Department of Civil Engineering.,16-17.

[13] ZHANG Zhizhen, GAO Feng.,2012 Experimental study on energy evolution of red sandstone under uniaxial compression[J]. Rock Mechanics and Rock Engineering.,31(5):953-962. 